\title{
ANALYSIS OF PHENOLS AND OXIDATION INTERMEDIATES IN COKING WASTEWATER BY HPLC
}

\author{
GUO YANG, *a XINGYONG LIU, ${ }^{a} H U$ YANG ${ }^{a}$ XIE MA, ${ }^{a}$ AND YUJUN FENG *b
}

${ }^{a}$ College of Materials and Chemical Engineering, Sichuan University of Science and Engineering, Zigong 643000, PR China.

${ }^{b}$ Polymer Research Institute, State Key Laboratory of Polymer Materials Engineering, Sichuan University, Chengdu 610065, PR China.

\section{ABSTRACT}

The simultaneous determination of phenol, cresol, polyphenol and their degradation products was important to evaluate the biodegradability of real wastewater. In the present study a reversed phase high performance liquid chromatography method was developed and validated for simultaneous determination of phenol $(\mathrm{PhOH}), o$-cresol $(o-\mathrm{C}), p$-cresol $(p-\mathrm{C})$, hydroquinone (HQ), benzoquinone (BQ), catechol (CTL), $p$-hydroxybenzoic acid $(p$-HBZO) and $p$-hydroxybenzaldehyde ( $p$-BZAL). The developed method was successfully applied to quantitative analysis of these compounds in raw and treated wastewater by CWAO. The highly toxic compounds, HQ and BQ, were totally removed; whereas $52.5 \%$ of $\mathrm{PhOH}, 59.4 \%$ of $o-\mathrm{C}$ and $57.7 \%$ of $p$-C in coking wastewater were degraded by CWAO over activated carbon catalyst. The degradation products including low-toxicity $p$-BZAL and $p$-HBZO were detected in the treated wastewater. The $\mathrm{pH}$ of wastewater was important to avoid generation of highly toxic compounds. CWAO using activated carbon as catalyst was feasible for pretreatment of coking wastewater. The established HPLC method was also used to simultaneously analyze phenols in other wastewater.

Keywords: Phenols; coking wastewater; HPLC; catalytic wet air oxidation

\section{INTRODUCTION}

Generated from coal coking, coal gas purification, and by-products recovery processes ${ }^{1}$, coking wastewater contained various toxic and biorefractory organic compounds, such as polyaromatic hydrocarbons, nitrogenous heterocyclic compounds and phenols ${ }^{2}$. Among these pollutants, phenols accounted for about $80 \%$ of total $\mathrm{COD}^{3}$, and their total concentration in coking wastewater varied from 400 to $1200 \mathrm{mg} \mathrm{L}^{-1}$ with coal and process used ${ }^{4}$. It was reported that about $50 \mathrm{mg} \mathrm{L}^{-1}$ of phenol in aqueous environment could lead to the biomass activity decline rapidly and inhibit the reproduction of micro-organisms ${ }^{5}$. The US Environmental Protection Agency (EPA) set a limitation of $0.1 \mathrm{mg} \mathrm{L}^{-1}$ of phenol in wastewater ${ }^{6,7}$, and the World Health Organization (WHO) specified $0.001 \mathrm{mg} \mathrm{L}^{-1}$ as concentration limit in potable water $^{8}$.

Due to the toxicity of phenols and lower removal efficiency, high concentration phenolic industrial effluents was unfavorable to direct biotreatment $^{3,9}$. Catalytic wet air oxidation (CWAO) which degraded pollutant under mild reaction conditions $\left(120-160{ }^{\circ} \mathrm{C}, 0.1-1.0 \mathrm{MPa}\right.$ of oxygen partia pressure), was considered as a potential pretreatment in term of reduction the toxicity of phenol ${ }^{10}$. However, more toxic intermediates such as hydroquinone (HQ), benzoquinone (BQ) and catechol (CTL), were probably generated in the process of phenolic oxidation depending on the reaction condition ${ }^{11,12}$. These toxic compounds negatively influence the biodegradability of the pretreated wastewater by CWAO.

Various analytical methods were reported on the analysis of phenol and cresol in water and wastewater. The most frequently employed method for analysis of total phenols was ultraviolet-visible absorbance measurement after reaction with 4 -aminoantipyrine ${ }^{13}$, but such a colorimetric method cannot determine the concentrations of individual phenols. Nistor et al. used enzymebased biosensors as a rapid determination method of phenol ${ }^{14}$. However, the obtained results were overestimated, which greatly limit its applications. Gas chromatography (GC) and HPLC were also used to analyze phenols. Nonetheless, the direct analysis of phenols using GC was problematic because of the thermal instability of phenols ${ }^{15}$. So, GC analysis of phenols was usually supported after precolumn derivatization ${ }^{16}$. By contrast, a major advantage of HPLC over GC was the lower temperature used in the process of analysis, which reduced the risk of decomposition of thermally unstable substance. Additionally, HPLC also offer the advantages of speed, resolution, high sensitivity and specificity. Consequently, HPLC particularly reversed-phase liquid chromatography was frequently used for quantitative analysis of phenol and cresol in natural water, potable water and wastewater ${ }^{17,18}$.

Besides phenol and cresol, HQ and CTL were identified by HPLC as the intermediates of phenol oxidation over copper oxide and metal oxides composite catalyst ${ }^{19}$. Eftaxias et al. ${ }^{20}$ reported that $p$-hydroxybenzoic acid was phenol oxidation product using $\mathrm{AC}$ and $\mathrm{Fe} / \mathrm{AC}$ catalysts in acidic solution. Rode ${ }^{21}$ and Santos ${ }^{22}$ determined the concentration of $p$-hydroxybenzyl alcohol ( $p$-BZOL), $p$-hydroxybenzaldehyde ( $p$-BZAL) and $p$-hydroxybenzoic acid ( $p$-HBZO) in the CWAO of cresol over $\mathrm{Co}_{3} \mathrm{O}_{4}$ and AC catalyst. Font et al. ${ }^{23}$ reported a HPLC method allowed identifying 26 different compounds including phenol, $o$-cresol and intermediates in the treated phenol solution. These HPLC methods were merely used to determine the oxidation products yielded from either phenol or cresol solution. In fact, phenol, cresol, catechol and hydroquinon, the most important constituents in inhibiting biodegradation, always simultaneously existed in aqueous solution. Consequently, the reported methods were limited in determination of phenols in real wastewater. Furthermore, when applying these HPLC method to analysis of real wastewater, some analytes were probably interfered because of the matrix effect. Therefore, it was necessary to develop a validated HPLC method to simultaneously determine the phenol, cresol, catechol and hydroquinon in real wastewater.

In our previous work, activated carbon aminated at $650{ }^{\circ} \mathrm{C}$ showed high adsorption capacity for phenol ${ }^{24}$. Moreover, pretreatment by CWAO over aminated carbon significantly improved the biodegradation of coking wastewater ${ }^{25}$. The $\mathrm{BOD}_{5} / \mathrm{COD}$ ratio increased from 0.23 for the raw coking wastewater to 0.84 of the effluent pretreated by CWAO. However, the remained phenolic compounds occurring in the treated effluent were not identified and quantified.

In this work, coking wastewater was pretreated by $\mathrm{CWAO}$ with the aminated AC catalyst at $150{ }^{\circ} \mathrm{C}$ and $0.2 \mathrm{MPa}$ of oxygen partial pressure. A liquid chromatographic procedure for sensitive and accurate analysis of phenol $(\mathrm{PhOH}), o$-cresol $(o-\mathrm{C}), p$-cresol $(p-\mathrm{C}), \mathrm{CTL}$ and intermediates $(p$-BZAL, $p$-HBZO, BQ, HQ) has been optimized, validated and then applied to analysis of the treated coking wastewater in different reaction time.

\section{EXPERIMENTAL}

\subsection{Chemical and Regents}

$\mathrm{NH}_{3}$-striped coking wastewater was obtained from Anshan Iron and Steel Groups Corporation (Anshan, China). The COD was $8092 \mathrm{mg} \mathrm{L}^{-1}$, and $\mathrm{pH}$ was 9.8. The main phenolic contaminants in coking wastewater included $\mathrm{PhOH}$ $p$-C and $o-\mathrm{C}$, which based on the qualitative analysis results of GC-MS (result not given). AC was obtained from Xinsen Carbon Industry Co. Ltd (Pingluo, China). Acetonitrile (HPLC-grade) was purchased from Fisher Scientific UK Ltd. Other chemicals were of analytical-grade unless specified otherwise. Deionized water was generated from an all-glass water purification system.

2.2 Preparation of Standard Working Solutions and Wastewater Samples

The stock solutions were obtained by dissolving $25.0 \mathrm{mg}$ of $\mathrm{HQ}$, BQ, CTL, $p$-HBZO, $p$-BZAL, $p$-C, $o$-C and $50.0 \mathrm{mg} \mathrm{PhOH}$ in $10 \%(\mathrm{v} / \mathrm{v})$ acetonitrile aqueous solution with eight $25-\mathrm{mL}$ volumetric flasks, respectively. Five standard solutions with different concentration levels were prepared by diluting the mixed stock solutions with the acetonitrile aqueous solution. All the standard solutions were stored at $4{ }^{\circ} \mathrm{C}$ in the refrigerator to be protected from light.

As for the analysis of coking wastewater, $1.0 \mathrm{~mL}$ coking wastewater was diluted to $10.0 \mathrm{~mL}$ with deionized water. All the sample solutions were filtered through $0.45 \mu \mathrm{m}$ nylon membrane filter prior to analysis. 
2.3 Chromatographic Conditions

A HPLC analysis was performed on an Agilent 1100 series chromatograph, equipped with a G1322A degasser, a G1310A quaternary pump, a G1316A TCC (thermostat column compartment), a G1314B VWD (Variable Wave Detector) and an Agilent Technology C18 XDB column $(5 \mu \mathrm{m}, 4.6 \times 150 \mathrm{~mm})$. The mobile phase was a mixture of solvents A (acetonitrile) and B (phosphoric acid aqueous solution, $\mathrm{pH}=2.5$ ). A gradient program was used to give adequate resolution between the analytes. The gradient started from 5-10\% (v/v) of B in the first $20 \mathrm{~min}, 10-36 \%(\mathrm{v} / \mathrm{v})$ of $\mathrm{B}$ at $20-33 \mathrm{~min}$ and last went to a $10-\mathrm{min}$ isocratic elution with $90 \%$ of $\mathrm{B}$ and $10 \% \mathrm{~A}$. During the whole analysis process,

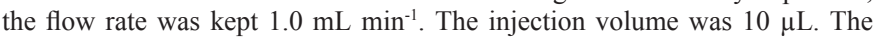
column temperature was $30{ }^{\circ} \mathrm{C}$. The detector signal was set to $276 \mathrm{~nm}$ at the first $5.5 \mathrm{~min}$, then from $5.6 \mathrm{~min}$ to $7.0 \mathrm{~min}$ the wavelength was $293 \mathrm{~nm}$ for the detection of benzoquinone, after which the signal was set back to $276 \mathrm{~nm}$.

2.4 Validation of the Method

The validation of the method was evaluated in terms of linearity and range, precision, accuracy, limit of detection (LOD) and limit of quantitation (LOQ).

The calibration curves were constructed by using a least square linear regression analysis on the mixture of standards at the five different concentration level. The form of the linear regression equation was $y=a x+b$, where $y$ and $\mathrm{x}$ were the peak area and concentration of the compound, respectively. The correlation coefficients $\mathrm{R}^{2}$ was used to characterize linearity of the method.

The precision of the method was assessed with repeatability in intra-day and inter-day. The standard solution was analyzed in three replicates within 24 $\mathrm{h}$ to evaluate the intra-day precision. The inter-day precision was performed by analysis of three replicates for three consecutive days. The results of intra-day and inter-day precisions were expressed as relative standard deviation (RSD).

$$
\mathrm{RSD} \%=\frac{\mathrm{SD}}{\mathrm{M}} \times 100
$$

where $\mathrm{SD}$ is the standard deviation, $\mathrm{M}$ is the mean of the sample.

The accuracy of the method was evaluated by average recovery in intraday and inter-day, and the recovery $(\mathrm{R})$ could be expressed as follows:

$$
\mathrm{R} \%=\frac{\mathrm{C}_{\text {spiked }}-\mathrm{C}_{\text {unspiked }}}{\mathrm{C}_{\text {stan dard }}} \times 100
$$

Where $\mathrm{C}_{\text {spiked }}$ is the concentration of sample spiked with calibration standards $\left(\mathrm{mg} \mathrm{L}^{-1}\right), \mathrm{C}_{\text {unspiked }}$ is the unspiked sample concentration $\left(\mathrm{mg} \mathrm{L}^{-1}\right)$, and $\mathrm{C}_{\text {standard }}$ is the spiked concentration $\left(\mathrm{mg} \mathrm{L}^{-1}\right)$. The concentrations of spiked and unspiked samples were calculated according to the corresponding peak area.

LOD was the lowest concentration of the sample detected by the instrument, whereas LOQ was the lowest concentration of a compound that can be quantitated. The former was calculated by a signal-to-noise ratio of $3: 1$, while LOQ was calculated by a signal-to-noise ratio of 10:1.

2.5 CWAO of Coking Wastewater over modified AC

An aminated AC was used as a catalyst in CWAO of coking wastewater. The parent activated carbon was crushed into particles of 16-40 mesh, washed by diluted $\mathrm{HCl}$ solution to remove ash, and then dry at $120{ }^{\circ} \mathrm{C}$ for $24 \mathrm{~h}$. The demineralized AC was calcined in a quartz tube furnace at $650{ }^{\circ} \mathrm{C}$ for $2 \mathrm{~h}$ and cooling naturally to room temperature. A mixed gas (ammonia and nitrogen) flowed through the quartz tube from start to end of aminated treatment. The flow rates of ammonia and nitrogen were 20 and $60 \mathrm{~mL} \mathrm{~min}^{-1}$, respectively.

The CWAO experiment was performed in a fixed bed reactor with a stainless steel tube of $12 \mathrm{~mm}$ in internal diameter and $500 \mathrm{~mm}$ in length, which was placed in an electrically heated oven with a PID temperature controller. The reaction temperature was determined with a thermocouple located in the catalyst bed. $10.0 \mathrm{~mL}$ of the modified $\mathrm{AC}$ was loaded into the reactor. Wastewater and air were mixed and fed into the bottom of the reactor. The $\mathrm{CWAO}$ treatment was performed at $150{ }^{\circ} \mathrm{C}$ and total pressure of $1.0 \mathrm{MPa}$. The flow rates of wastewater and gas were 0.5 and $50(\mathrm{STP}) \mathrm{mL} \mathrm{min}^{-1}$, respectively. Before running the reaction, air was adjusted to the set pressure and flow rate, then heat was applied to the reaction system. Once the set temperature was reached, the pump started to feed wastewater. The details referred to the previous work ${ }^{25}$.

\section{RESULTS AND DISCUSSION}

3.1 HPLC analytical procedure

A good separation condition should meet the requirements that the peaks of analytes have baseline separation with adjacent peaks within a short analysis time as far as possible. In the preliminary chromatographic studies, the methanol/water was used as gradient elution phase. A good separation was obtained for analyzing the mixed standard solution. However, when separating the coking wastewater sample, the methanol/water mixed system resulted in the problems such as the broad peak of phenol, baseline drift, and higher column pressure. After several trials, mixture of acetonitrile and phosphoric acid aqueous solution $(\mathrm{pH}=2.5)$ was finally chosen as the mobile phase because of good separation and lower column pressure for both standard solution and real wastewater.

The HPLC chromatogram of standard samples is displayed in Fig. 1. The standard samples were well separated from each other under the established HPLC condition. The retention times were $3.53 \mathrm{~min}$ for HQ, $6.77 \mathrm{~min}$ for BQ, $8.69 \mathrm{~min}$ for CTL, $10.19 \mathrm{~min}$ for $p$-HBZO, $14.80 \mathrm{~min} p$-BZAL, $17.87 \mathrm{~min}$ for $\mathrm{PhOH}, 30.29 \mathrm{~min}$ for $p$-C and $30.94 \mathrm{~min}$ for $o-\mathrm{C}$, respectively. The analytes were well separated under the established chromatographic condition.

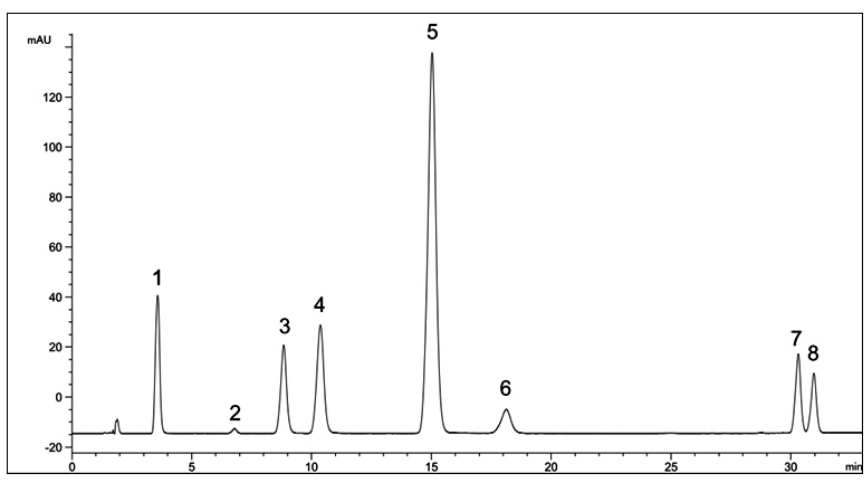

Fig. 1: Chromatogram of standard compounds: 1, HQ; 2, BQ; 3, CTL; 4 $p$-HBZO; 5, p-BZAL; 6, PhOH; 7, $p$-C; $8, o-\mathrm{C}$

For the purpose of quantitative analysis, the validation of the method was evaluated in terms of linearity and range, precision, accuracy, LOD and LOQ.

The linear regression equation, linear range and linear correlation coefficients are summarized in Table 1 . The linear correlation coefficients were observed with $\mathrm{R}^{2}>0.994$, indicating good linearity of the linear equations of objective compounds

Table 1. Linear range, linear equation and correlation coefficients for eight analytes.

\begin{tabular}{|c|c|c|c|}
\hline Compounds & $\begin{array}{c}\text { Linear range } \\
\left(\mathrm{mg} \mathrm{L}^{-1}\right)\end{array}$ & Linear equation & $\mathrm{R}^{2}$ \\
\hline $\mathrm{HQ}$ & $10-100$ & $\mathrm{y}=16.41 \mathrm{x}+0.805$ & 0.998 \\
\hline $\mathrm{BQ}$ & $40-100$ & $\mathrm{y}=0.69 \mathrm{x}-1.534$ & 0.999 \\
\hline $\mathrm{CTL}$ & $10-100$ & $\mathrm{y}=14.37 \mathrm{x}+6.016$ & 0.998 \\
\hline$p$-HBZO & $10-100$ & $\mathrm{y}=18.67 \mathrm{x}+31.170$ & 0.995 \\
\hline$p$-BZAL & $10-100$ & $\mathrm{y}=85.43 \mathrm{x}+10.741$ & 0.998 \\
\hline $\mathrm{PhOH}$ & $10-100$ & $\mathrm{y}=6.33 \mathrm{x}+1.812$ & 0.999 \\
\hline$p-\mathrm{C}$ & $10-100$ & $\mathrm{y}=12.58 \mathrm{x}+4.997$ & 0.998 \\
\hline$o-\mathrm{C}$ & $10-100$ & $\mathrm{y}=9.10 \mathrm{x}+3.284$ & 0.997 \\
\hline
\end{tabular}

Intra-day and inter-day precisions and accuracies are shown in Table 2. The intra-day and inter-day precisions of the eight analytes in different concentrations were about $5 \%$, suggesting the precision of the proposed method was fine. The intra-day and inter-day accuracies expressed as recoveries were in the range of $95.13-103.89 \%$ and $94.77-103.31 \%$ respectively denoting the accuracy of the method met the analytic requirement. 
Table 2. Accuracy and precision tests for eight analytes in coking wastewater.

\begin{tabular}{|c|c|c|c|c|c|}
\hline \multirow{2}{*}{ Compound } & \multirow{2}{*}{$\begin{array}{r}\text { Nominal } \\
\text { content } \\
\left(\mathrm{mg} \mathrm{L}^{-1}\right)\end{array}$} & \multicolumn{2}{|c|}{ Intra-day $(\mathrm{n}=3)$} & \multicolumn{2}{|c|}{ Inter-day $(\mathrm{n}=3)$} \\
\hline & & $\begin{array}{c}\text { Precision } \\
\text { (RSD\%) }\end{array}$ & $\begin{array}{c}\text { Accuracy } \\
(\%)\end{array}$ & $\begin{array}{c}\text { Precision } \\
(\mathrm{RSD} \%)\end{array}$ & $\begin{array}{c}\text { Accuracy } \\
(\%)\end{array}$ \\
\hline \multirow[t]{3}{*}{ HQ } & 10 & 3.80 & 97.87 & 3.18 & 96.96 \\
\hline & 50 & 3.72 & 101.10 & 5.37 & 95.88 \\
\hline & 100 & 4.76 & 103.89 & 5.06 & 98.64 \\
\hline \multirow[t]{3}{*}{ BQ } & 40 & 6.23 & 95.13 & 6.34 & 98.07 \\
\hline & 70 & 4.52 & 95.17 & 4.85 & 97.89 \\
\hline & 100 & 2.34 & 101.08 & 2.24 & 102.78 \\
\hline \multirow[t]{3}{*}{ CTL } & 10 & 4.12 & 95.34 & 6.42 & 94.77 \\
\hline & 50 & 3.09 & 98.81 & 3.44 & 97.24 \\
\hline & 100 & 2.28 & 103.10 & 2.67 & 100.88 \\
\hline \multirow[t]{3}{*}{$\mathrm{PhOH}$} & 10 & 3.04 & 99.53 & 4.20 & 103.31 \\
\hline & 50 & 3.16 & 102.08 & 2.89 & 99.40 \\
\hline & 100 & 3.54 & 100.24 & 4.13 & 99.65 \\
\hline \multirow[t]{3}{*}{$p-\mathrm{C}$} & 10 & 3.90 & 102.77 & 2.87 & 98.81 \\
\hline & 50 & 2.60 & 100.55 & 3.63 & 99.15 \\
\hline & 100 & 3.30 & 99.86 & 4.87 & 99.73 \\
\hline \multirow[t]{3}{*}{$o-\mathrm{C}$} & 10 & 0.95 & 96.48 & 3.57 & 101.23 \\
\hline & 50 & 3.96 & 102.75 & 3.96 & 102.75 \\
\hline & 100 & 3.75 & 101.72 & 3.75 & 101.72 \\
\hline \multirow[t]{3}{*}{$p$-HBZO } & 10 & 2.65 & 98.39 & 0.84 & 98.24 \\
\hline & 50 & 1.57 & 97.98 & 2.59 & 98.88 \\
\hline & 100 & 2.27 & 100.45 & 1.60 & 100.64 \\
\hline \multirow[t]{3}{*}{$p$-BZAL } & 10 & 2.42 & 97.42 & 3.44 & 98.84 \\
\hline & 50 & 3.43 & 99.14 & 1.34 & 99.60 \\
\hline & 100 & 3.01 & 100.84 & 3.34 & 99.14 \\
\hline
\end{tabular}

The LOD and LOQ values of eight compounds are calculated and listed in Table 3. Their values of LOD and LOQ were in the range of $0.06-4.84 \mathrm{mg} \mathrm{L}^{-1}$ and $0.21-16.13 \mathrm{mg} \mathrm{L}^{-1}$, respectively. The results were low enough for analysis of phenols in coking wastewater.

Table 3. LOD and LOQ for eight analytes in coking wastewater

\begin{tabular}{|c|c|c|}
\hline Compounds & LOD $\left(\mathrm{mg} \mathrm{L}^{-1}\right)$ & LOQ $\left(\mathrm{mg} \mathrm{L}^{-1}\right)$ \\
\hline HQ & 0.11 & 0.35 \\
\hline BQ & 4.84 & 16.13 \\
\hline CTL & 0.26 & 0.87 \\
\hline$p$-HBZO & 0.20 & 0.67 \\
\hline$p$-BZAL & 0.06 & 0.21 \\
\hline PhOH & 0.09 & 3.03 \\
\hline$p-C$ & 0.28 & 0.93 \\
\hline$o-C$ & 0.39 & 1.28 \\
\hline
\end{tabular}

In brief, the developed HPLC method was validated and sensitive for simultaneous analysis of the HQ, BQ, CTL, $p$-HBZO, $p$-BZAL, PhOH, $p$-C and $o-\mathrm{C}$; the precision and accuracy satisfied the requirements for analysis of coking wastewater. This method was applied to not only the phenolic solution but also the real industrial wastewater containing phenol, cresol and polyphenol.

\subsection{CWAO of Coking Wastewater}

In order to investigate the degradability of $\mathrm{PhOH}, p-\mathrm{C}$ and $o-\mathrm{C}$ in coking wastewater, the developed analytic method was used to determine the concentration of phenols and intermediates in coking wastewater before and after CWAO (Fig. 2). The target compounds in coking wastewater were recognized by comparing the retention times and UV spectra with standard references. As showed in Fig. 2a, five peaks (peak 1: HQ, peak 2: BQ, peak 6: $\mathrm{PhOH}$, peak 7: $p-\mathrm{C}$ and peak $8: o-\mathrm{C}$ ) present in the chromatogram of the raw wastewater.
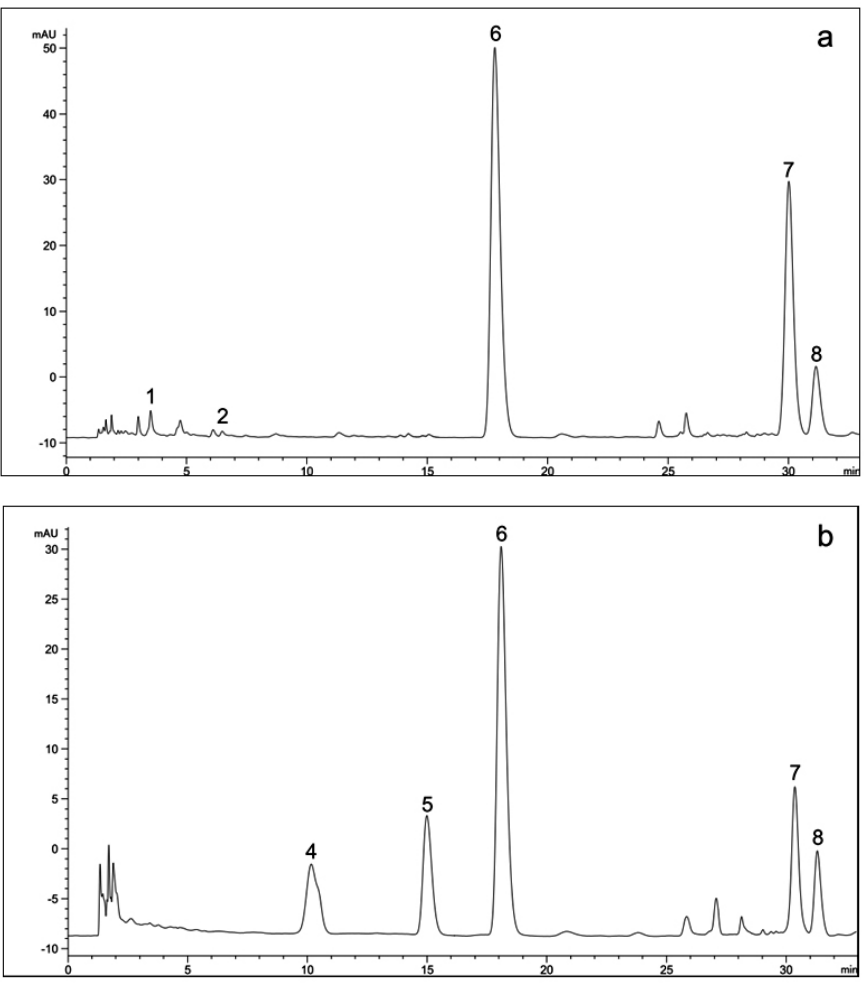

Fig. 2: Chromatograms of wastewater before (a) and after (b) treatmen by CWAO: 1, HQ; 2, BQ; 3, CTL; 4, $p$-HBZO; 5, p-BZAL; 6, PhOH; 7, p-C; $8, o-\mathrm{C}$.

The chromatogram of the treated wastewater is shown in Fig. 2b. With the disappearance of HQ (peak 1) and BQ (peak 2), as well as the decrease of phenols (peak 6, peak 7 and peak 8), other two peaks (peak 4, peak 5) appeared in the chromatogram of the treated wastewater. The result indicated that $p$-HBZO and $p$-BZAL were the oxidation products in the CWAO process. Stüber believed that phenol could react with carboxylic acid groups on the surface of carbon catalyst to form $p$-HBZO ${ }^{20}$. The generation of $p$-BZAL originated from the oxidation of $p-\mathrm{C}^{21}$. Initially, $p-\mathrm{C}$ was oxidized over carbon catalyst in $\mathrm{NaOH}$ solution generating $p$-hydroxybenzyl alcohol ( $p$-BZOL), and with the further oxidation of $p$-BZOL, $p$-BZAL started building up (Fig. 3). Therefore, it was reasonable to suppose that $p$-HBZO and $p$-BZAL were the oxidation products in CWAO of coking wastewater.<smiles>Cc1ccc(O)c(-c2cc(CO)cc(C(=O)O)c2)c1O</smiles>

Fig. 3: Oxidation pathway of $p-\mathrm{C}$ and $\mathrm{PhOH}{ }^{20,21}$ 
Moreover, according to the chromatography of treated wastewater (Fig. 2b), highly toxic intermediates including HQ, BQ and CTL were not detected. This indicated that toxic compounds were not yielded in the CWAO of coking wastewater with $\mathrm{pH}$ 9.8. Similar phenomenon was also reported in the CWAO of $\mathrm{PhOH}$ and $o$-C over AC catalyst at $\mathrm{pH} 8$ adjusted by sodium bicarbonate ${ }^{22}$. At $\mathrm{pH} 3.5, \mathrm{HQ}, \mathrm{CTL}$ and BQ were formed. Therefore, solution $\mathrm{pH}$ was a key factor in pretreatment of phenolic wastewater with CWAO.

Fig. 4 shows the evolution of phenols and oxidation products in 66-h tests at $1.0 \mathrm{MPa}$ of total pressure, $150{ }^{\circ} \mathrm{C}$ of reaction temperature. The concentration of $\mathrm{PhOH}, o-\mathrm{C}$ and $p-\mathrm{C}$ increased exponentially and then went to a plateau. The fast increase of phenols concentration was attributed to the decrease of adsorption capacity and deactivation of the catalyst, which was caused by oxidative coupling reactions of phenols ${ }^{10,26}$. At $66 \mathrm{~h}$ of reaction time, $52.5 \%$ of $\mathrm{PhOH}, 59.4 \%$ of $o-\mathrm{C}$ and $57.7 \%$ of $p$-C were removed, producing $30.7 \mathrm{mg} \mathrm{L}^{-1}$ $p$-BZAL and $4.94 \mathrm{mg} \mathrm{L}^{-1} p$-HBZO, respectively. It was apparent that $\mathrm{PhOH}$, $o-\mathrm{C}$ and $p-\mathrm{C}$ in coking wastewater were significantly degraded by CWAO.

(The abbreviation has been used in the legend of Fig. 4)

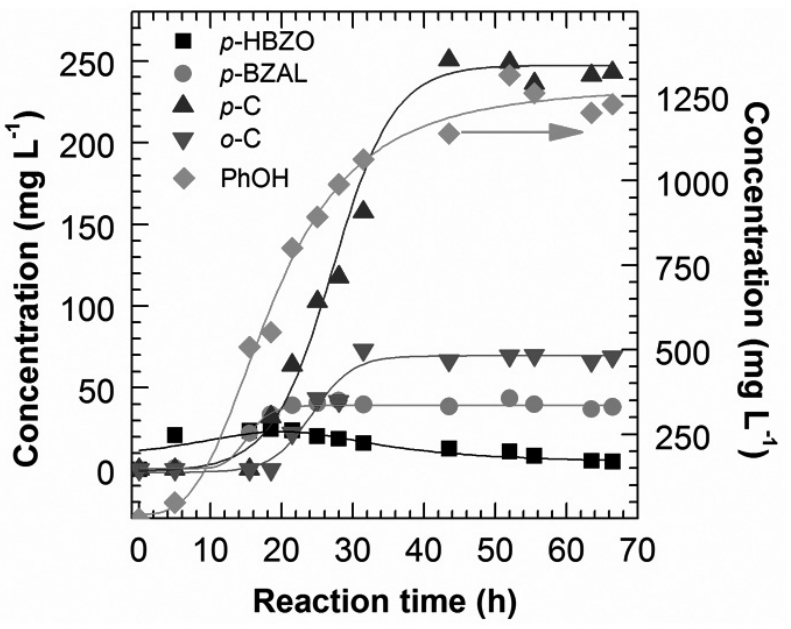

Fig. 4: Variation in concentration of $\mathrm{PhOH}, o-\mathrm{C}, p-\mathrm{C}, p$-BZAL and $p$-HBZO in CWAO process.

\section{CONCLUSIONS}

A HPLC method was developed for simultaneous determination of $\mathrm{PhOH}$, $o-\mathrm{C}, p-\mathrm{C}, \mathrm{CTL}, \mathrm{HQ}, \mathrm{BQ}, p-\mathrm{BZAL}$ and $p$-HBZO. The linearity, precision, accuracy, LOD and LOQ suggested that the method was validated and sensitive. The established method was applied to analysis of the concentrations of phenols and hazardous intermediates in the raw and treated coking wastewater. The results indicated that $\mathrm{PhOH}, o-\mathrm{C}$ and $p-\mathrm{C}$ were effectively degraded by CWAO, while the higher toxic intermediates including HQ, CTL and BQ were not presented in the treated coking wastewater. The toxicity of coking wastewater decreased by $\mathrm{CWAO}$ with $\mathrm{AC}$ catalyst, which was favorable to integration of bio-treatment. The established HPLC method was also applied to analyzing phenols in other industrial effluent and monitoring $\mathrm{PhOH}, p-\mathrm{C}, o-\mathrm{C}$, $p$-BZAL and $p$-HBZO in aqueous environment.

\section{ACKNOWLEDGMENTS}

The authors would like to acknowledge the financial support provided by The Applied Basic Research Program of the Education Department in Sichuan (no. 14ZB0209), and The Training Project of Sichuan University of Science and Engineering (no.2013PY02).

$\begin{array}{ll}\text { Appendix } & \text { activated carbon } \\ \text { AC } & \text { benzoquinone } \\ \text { BQ } & p \text {-hydroxybenzaldehyde } \\ p \text {-BZAL } & p \text {-hydroxybenzyl alcohol } \\ p \text {-BZOL } & o \text {-cresol } \\ o \text {-C } & p \text {-cresol } \\ p \text {-C } & \text { the concentration of sample spiked, } \mathrm{mg} \mathrm{L}^{-1} \\ \mathrm{C}_{\text {spiked }} & \text { the unspiked sample concentration, } \mathrm{mg} \mathrm{L}^{-1} \\ \mathrm{C}_{\text {unspiked }} & \text { the spiked concentration, } \mathrm{mg} \mathrm{L}^{-1} \\ \mathrm{C}_{\text {standard }} & \text { catechol } \\ \mathrm{CTL} & p \text {-hydroxybenzoic acid } \\ p \text {-HBZO } & \text { hydroquinone } \\ \mathrm{HQ} & \text { limit of detection, mg L } \\ \mathrm{LOD} & \text { limit of quantitation, mg L } \\ \text { LOQ } & \text { means of the sample } \\ \mathrm{M} & \text { phenol } \\ \mathrm{PhOH} & \text { recovery, } \% \\ \mathrm{R} & \text { relative standard deviation } \\ \mathrm{RSD} & \text { standard deviation } \\ \mathrm{SD} & \end{array}$

\section{REFERENCES}

[1] M. Ghose, Water Res. 36, 1127, (2002).

[2] J. Wanner, Water Sci. Technol. 29, 193, (1994).

[3] Y. M. Kim, D. Park, D. S. Lee, J. M. Park, J. Hazard. Mater. 152, 915, (2008).

[4] I. Vázquez, J. Rodríguez-Iglesias, E. Marañón, L. Castrillón, M. lvarez, J. Hazard. Mater. 147, 395, (2007)

[5] R. L. Autenrieth, J. S. Bonner, A. Akgerman, M. Okaygun, E. M. Mccreary, J. Hazard. Mater. 28, 29, (1991).

[6] C. Karigar, A. Mahesh, M. Nagenahalli, D. J. Yun, Biodegradation 17, 47, (2006).

[7] I. Machón, H. López, J. Rodríguez-Iglesias, E. Marañón, I. Vázquez, Environ. Modell. Softw. 22, 1382, (2007)

[8] S. P. Kamble, P. A. Mangrulkar, A. K. Bansiwal, S. S. Rayalu, Chem. Eng. J. 138, 73, (2008).

[9] J. H. Fan, L. M. Ma, J. Hazard. Mater. 164, 1392, (2009).

[10] A. Quintanilla, J. A. Casas, J. J. Rodriguez, Appl. Catal. B. Environ. 76, 135, (2007).

[11] A. Santos, P. Yustos, T. Cordero, S. Gomis, S. Rodriguez, F. GarciaOchoa, Catal. Today 102, 213, (2005).

[12] M. E. Suárez-Ojeda, J. Carrera, I. S. Metcalfe, J. Font, Chem. Eng. J. 144, 205, (2008).

[13] M. Rodriguezalcala, P. Yanezsedeno, L. M. P. Diez, Talanta 35, 601, (1988).

[14] C. Nistor, A. Rose, M. Farré, L. Stoica, U. Wollenberger, T. Ruzgas, D. Pfeiffer, D. Barceló, L. Gorton, J. Emnéus, Anal. Chim. Acta 456, 3, (2002).

[15] E. Gonzalez-Toledo, M. D. Prat, M. F. Alpendurada, J. Chromatogr. A 923, 45, (2001)

[16] E. L. B. Lourenco, A. Ferreira, E. Pinto, M. Yonamine, S. H. P. Farsky, Chromatographia 63, 175, (2006).

[17] E. M. Basova, V. M. Ivanov, K. V. Novikova, J. Anal. Chem. 57, 434, (2002).

[18] C. Huang, G. M. Zhou, H. J. Peng, Z. X. Gao, Anal. Sci. 21, 565, (2005)

[19] A. Pintar, J. Levec, Ind. Eng. Chem. Res. 33, 3070, (1994).

[20] A. Eftaxias, J. Font, A. Fortuny, A. Fabregat, F. Stuber, Appl. Catal. B. Environ. 67, 12, (2006)

[21] C. V. Rode, M. V. Sonar, J. M. Nadgeri, R. V. Chaudhari, Org. Process. Res. Dev. 8, 873, (2004).

[22] A. Santos, P. Yustos, S. Rodriguez, F. Garcia-Ochoa, Appl. Catal. B Environ. 65, 269, (2006).

[23] M. E. Suárez-Ojeda, A. Fabregat, F. Stüber, A. Fortuny, J. Carrera, J Font, Chem. Eng. J. 132, 105, (2007)

[24] G. Yang, H. Chen, H. Qin, Y. Feng, Appl. Surf. Sci. 293, 299, (2014).

[25] H. Chen, G. Yang, Y. Feng, C. Shi, S. Xu, W. Cao, X. Zhang, Chem. Eng. J. 198-199, 45, (2012).

[26] C. Creanga Manole, C. Ayral, C. Julcour Lebigue, A. M. Wilhelm, H. Delmas, Int. J. Chem. React. Eng. 5, 65, (2007). 